\title{
ONE-POT SYNTHESIS, PHARMACOLOGICAL EVALUATION, DOCKING STUDY, AND DFT CALCULATIONS FOR SELECTED IMIDAZOLIDINE-2,4-DIONES
}

\author{
Zanko Hassan Jawhar ${ }^{\mathrm{a}}$, Hiwa Omer Ahmad ${ }^{\mathrm{b}, *}$, Asmaa Awni Haydar ${ }^{\mathrm{c}}$, Halala Abas Abdullah ${ }^{\mathrm{d}}$, Sawza Abdulsalam Mahamad ${ }^{\mathrm{d}}$
}

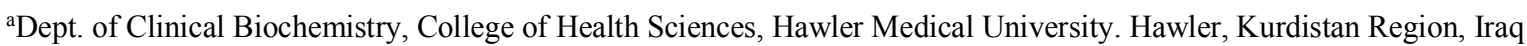

${ }^{b}$ Dept. of Pharmaceutical Chemistry, College of Pharmacy, Hawler Medical University. Hawler, Kurdistan Region, Iraq (hiwaomer@pha.hmu.edu.iq)

'Dept. of pharmacology, College of Pharmacy, Hawler Medical University. Hawler, Kurdistan Region, Iraq

${ }^{\mathrm{d}}$ Dept. of chemistry, College of Science, Soran University, Kurdistan Region, Iraq

Received: Sept. 2018 / Accepted: Nov., 2018 / Published: Dec., 2018

https://doi.org/10.25271/sjuoz.2018.6.4.541

\begin{abstract}
:
The title compounds with different 5-substituted imidazolidine-2,4-dione were synthesized through a solvent-free reaction. Imidazolidine-2,4-dione derivatives are found to be an active pharmacophore for design and development of various bioactive lead compounds. Positive values of energy obtained for compound $\mathbf{1}$ and $\mathbf{3}$, while a negative value for compound $\mathbf{2}$ was calculated by DFT in Gaussian. keto-enol tautomerism was supported by energy values and indicated the most stable tautomeric form. The biological evaluation has been supported by docking studies using molecular operating environment program to show binding with androgen receptor.
\end{abstract}

KEYWORDS: imidazolidine-2,4-dione derivatives, Prostate cancer, computational study, Energy, biological activity.

\section{INTRODUCTION}

The imidazolidine-2,4-dione (hydantoin) is a common 5membered ring containing a reactive cyclic used in medicinal chemistry because of its broad spectrum of biological activity. They have a number of biological activities as antiarrhythmic, anti-inflammatory, antitumor, and antidiabetic properties, in addition to the herbicidal and fungicidal activity (Cheng et al., 2008; Colacino et al., 2007; Ghanbari et al., 2014; Katritzky et al., 1998; Nefzi et al., 2000). There were a number of methods have been reported for the synthesis of 5- substituted analogs of hydantoins including multi-step methods, one-pot, solid-phase and microwaveassisted. (Li, 2010; J Safari et al., 2009; Javad Safari et al., 2010) H-bonds are the most important supramolecular synthons for assembling complex system and binding in vivo and vitro. (Bisello et al., 2017) Two $\mathrm{N}-\mathrm{H}$ and two $\mathrm{C}=\mathrm{O}$ acceptors are present to form intermolecular H-bonding in imidazolidine-2,4-dione derivatives (Bisello et al., 2017; Etter, 1990).

Several marketed hydantoin moieties are present as drugs such as anticonvulsant medications phenytoin (Tikhonov \& Zhorov, 2017) and etotoin, nilutamide, a postsynaptic muscle relaxant dantrolene, or an aldose reductase inhibitor sorbinil with different substituents at 1-, 3-, and 5-, positions. These substituents are giving different chemical and physical properties to the molecules. (Law et al., 2013) Baeyer company in 1861 has first achieved hydantoin, namely imidazolidine-2,4-dione. (Baeyer, 1861) Substituents on the 5- position have found to increase potency, while, substituent at position-1 decreases potency. Therefore, type of polar and polar group that were substituted on the position 1 and 5 affect the potency of hydantoin against cancer. A bulky group on the position 3 will also decrease activity rather than methyl group (M. Zhang et al., 2017). Androgen receptor AR antagonists is a soluble protein that used widely in a series of clinical application such as agonists are employed for hypogonadism, while antagonists are used for prostate cancer therapy (Scheme 1). (Gao et al., 2005)

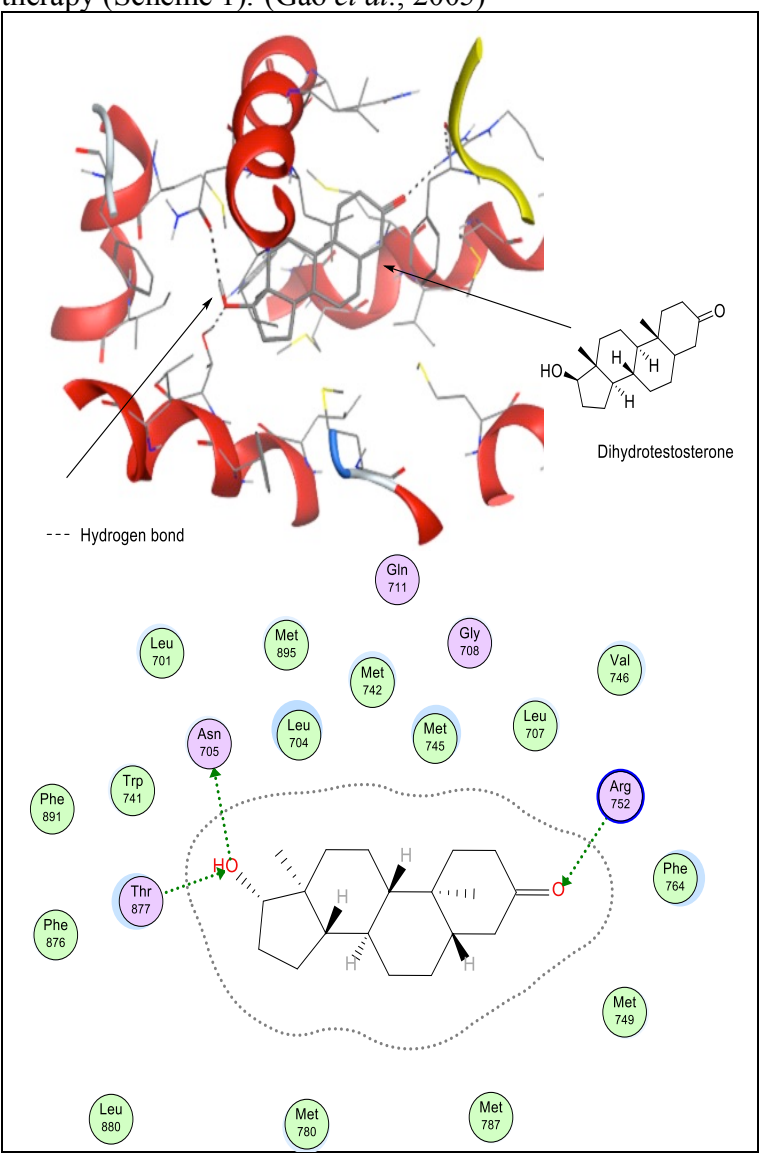

Scheme 1. AR-DHT co-crystal structure (PDB ID: 2AMA). The key residues around the ligand were shown. Hydrogen bonds were shown as dashed lines.

Researchers recently summarized a large number of drug and drug-like molecule that bind to the AR including substituted

\footnotetext{
* Corresponding author

This is an open access under a CC BY-NC-SA 4.0 license (https://creativecommons.org/licenses/by-nc-sa/4.0/)
} 
hydantoin and thiohydantoins. (Nique et al., 2012; X. Zhang et al., 2006; Zuo et al., 2017) The aim of this study is free solvent synthesis of selected 5-substituted moiety of hydantoins by using corresponding amino acids reacting with urea. The biological activity of the synthesized compounds was studied on some of gram positive bacteria and gram negative bacteria. Hydantoins have shown a wide spectrum of biological activity because of 5-cyclic ring containing carbonyl and N-H groups.

We are also involved to study energetics of hydantoin compounds including thermodynamic experiments and provide an insight on the effect of substitution on the C5 in the hydantoin ring, using wide range of substituents on protonation.

The molecular geometry was done for several compounds by Gaussian 09w program in a gas phase using different level of theory. MOE program has used to study between hydantoin and AR based the molecular structure.

\section{EXPERIMENTAL SECTION}

\subsection{Materials and Methods}

Infrared spectra were recorded in the range $4000-600 \mathrm{~cm}^{-1}$ using a Shimadzu Scientific Instruments' IR, as $\mathrm{KBr}$ disc. Samples were either thin films or powders. All absorptions are quoted in $\mathrm{cm}^{-1}$. ${ }^{1} \mathrm{H}-\mathrm{NMR}$ and ${ }^{13} \mathrm{C}$-NMR spectra were recorded on Brukeravance $(500 \mathrm{MHz})$ spectrometer. Chemical shifts are expressed in parts per million downfield from tetra-methylsilane as an internal standard. NMR spectra were recorded in solutions in the deuterated solvent mentioned.

\subsection{Molecular Modeling}

Gaussian $09 \mathrm{~W}$ was used to perform standard initio molecular orbital calculations. (Frisch et al., 2016) employing the B3LYP1 functional and the 6-31(p,d,f) basis set for all atoms. (Becke, 1993)

The enthalpy of formation of these compounds was estimated after the consideration of the following gas-phase working reactions:

\subsection{Energy Minimization Procedure}

The chemical compounds with the correct stereochemistry were drawn on Chemdraw professional 16.0 and stored in mol format in Gaussian view 5.0. The structure was recalled in molecular operating environment (MOE), and all hydrogen atoms were added.

\subsection{Docking Study}

All the molecular modeling calculations and docking simulation studies were performed utilizing Molecular Operating Environment (MOE®) 2014.091. The threedimensional X-ray structure of AR (PDB code 2AMA) was downloaded from protein Data banking. (Pereira de JesusTran et al., 2006)

\subsection{Chemistry}

2.5.1 General procedure for the synthesis of 5- substituted imidazolidine-2,4-diones: Corresponding amino acids and urea were mixed in a round bottom flask together at $160^{\circ} \mathrm{C}$. After 5 minutes, the temperature was increased to $190^{\circ} \mathrm{C}$ and a yellow vapour was observed inside the condenser. The mixture was allowed to heat under reflux at the same temperature for 20 minutes. Water was then added to the hot mixture. The mixture was then put in a refrigerator for the product to precipitate. The precipitant was collected and dried at room temperature. The product was purified by column chromatography on silica gel using $\mathrm{CH}_{2} \mathrm{Cl}_{2}$ /ethyl acetate $(80: 20)$.

\section{5-benzylimidazolidine-2,4-dione (1)}<smiles>CC1(C)CC(=O)NC1=O</smiles>

\section{1}

L-phenylalanine (1.0 g, $6.05 \mathrm{mmol})$ and urea $(2.3 \mathrm{~g}, 38.20 \mathrm{mmol})$ were mixed together and heated under stirring. yield 30\%, M.p. 188-189 ${ }^{\circ} \mathrm{C}$. HRMS calculated for $\mathrm{C}_{10} \mathrm{H}_{10} \mathrm{~N}_{2} \mathrm{O}_{2}$ $\mathrm{m} / \mathrm{z}$ [MS EI] ${ }^{+}$190.0742; found 190.0742); ${ }^{1} \mathrm{H}-\mathrm{NMR}(500 \mathrm{MHz}$ DMSO): $\delta 7.55$ (br s, $1 \mathrm{H}, \mathrm{NH}_{3}$ ), $\delta$ 7.35-7.16 (m, 5H, C6H5), $\delta$ $5.27\left(\right.$ br s, $\left.1 \mathrm{H}, \mathrm{NH}_{1}\right), \delta 4.28$ (ddd J=9.5, 3.7, $1.2 \mathrm{~Hz}, 1 \mathrm{H}, \mathbf{H}_{\mathrm{c}}$ ), $\delta$ $3.27\left(\mathrm{dd} \mathrm{J}=14.0,3.7 \mathrm{~Hz}, 1 \mathrm{H}, \mathbf{H}_{6 \mathrm{a}}\right), \delta 2.84(\mathrm{dd}, \mathrm{J}=13.9,9.4 \mathrm{~Hz}, 1 \mathrm{H}$, $\left.\mathbf{H}_{6 \mathrm{~b}}\right) ; 13 \mathrm{C}$ NMR (100 MHz, CDCI3): $\delta 175.1\left(\mathrm{C}_{2}\right), \delta 157.0\left(\mathrm{C}_{4}\right)$, $\delta$ 135.6-126.6 (Ar), $\delta 58.3\left(\mathrm{C}_{5}\right), \delta 36.4\left(\mathrm{C}_{6}\right)$. IR (neat): vmax= $1706,1775 \mathrm{~cm}^{-1}(\mathrm{C}=\mathrm{O})$.

\section{5-(2-(methylthio) ethyl) imidazolidine-2,4-dione (2)}

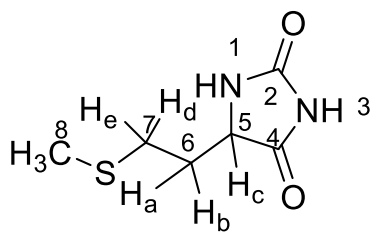

2

L-methionine (1.5g, $10.05 \mathrm{mmol})$ and urea (1.8 g, $29.90 \mathrm{mmol})$ were mixed together and heated under stirring.

Yield $=25.0 \%$, M.p. 107-109 ${ }^{\circ} \mathrm{C}$, HRMS calculated for $\mathrm{C}_{6} \mathrm{H}_{10} \mathrm{~N}_{2} \mathrm{O}_{2} \mathrm{~S} \mathrm{~m} / \mathrm{z}$ [MS EI] ${ }^{+}$174.0462; found 174.0463; ${ }^{1} \mathrm{H}-\mathrm{NMR}$ (500 MHz DMSO): $\delta 10.69$ (br s, $1 \mathrm{H}, \mathrm{NH}_{3}$ ), $\delta 8.04$ (br s, $1 \mathrm{H}$, $\left.\mathrm{NH}_{1}\right), \delta 4.15$ (ddd, $\left.J=7.9,4.6,1.3 \mathrm{~Hz}, 1 \mathrm{H}, \mathbf{H}_{\mathrm{c}}\right), \delta 2.60(\mathrm{t}, J=7.5$ $\mathrm{Hz}, 2 \mathrm{H}, \mathbf{H}_{\mathrm{d}}$ and $\left.\mathbf{H}_{\mathrm{e}}\right), \delta 2.32\left(\mathrm{~s}, 3 \mathrm{H}, \mathbf{H}_{8}\right), \delta 2.04-1.94(\mathrm{~m}, 1 \mathrm{H}$, $\left.\mathbf{H}_{\mathrm{a}}\right), \delta 1.88-1.75\left(\mathrm{~m}, 1 \mathrm{H}, \mathbf{H}_{\mathrm{b}}\right) \cdot{ }^{13} \mathrm{C}-\mathrm{NMR}\left(126 \mathrm{MHz}, \mathrm{d}_{6}\right.$-DMSO): $\delta 176.2\left(\mathrm{C}_{2}\right), \delta 156.3\left(\mathrm{C}_{4}\right), \delta 57.0\left(\mathrm{C}_{5}\right), \delta 31.5\left(\mathrm{C}_{6}\right), \delta 31.5\left(\mathrm{C}_{7}\right), \delta$ $14.40\left(\mathrm{C}_{8}\right)$.

\section{5-((1H-indol-3-yl) methyl) imidazolidine-2,4-dione (3)}

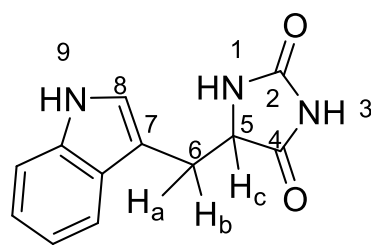

3

L-tryptophan (0.5 g, $2.4 \mathrm{mmol})$ and urea $(0.4 \mathrm{~g}, 7.3 \mathrm{mmol})$ were mixed together and heated under stirring.

Yield $=40.0 \%$, M.p. $112-113^{\circ} \mathrm{C}$, HRMS calculated for $\mathrm{C}_{12} \mathrm{H}_{11} \mathrm{~N}_{3} \mathrm{O}_{2} \mathrm{~m} / \mathrm{z}$ [ES] 229.0853 ; found $229.0851 ;{ }^{1} \mathrm{H}-\mathrm{NMR}(500$ MHz DMSO): $\delta 7.97$ (br s, $\left.1 \mathrm{H}, \mathrm{NH}_{3}\right), \delta 7.61(\mathrm{~d}, J=7.9 \mathrm{~Hz}, 1 \mathrm{H}$, Ar), $\delta 7.37(\mathrm{~d}, J=1.2 \mathrm{~Hz}, 1 \mathrm{H}, \mathrm{Ar}), \delta 7.18\left(\mathrm{~d}, J=2.4 \mathrm{~Hz}, 1 \mathrm{H}, \mathbf{H}_{8}\right)$, $\delta 5.49\left(\right.$ br s, $\left.1 \mathrm{H}, \mathrm{NH}_{1}\right), \delta 7.11$ (ddd, $J=8.2,7.0,1.2 \mathrm{~Hz}, 1 \mathrm{H}$, Ar), $\delta 7.03$ (ddd, $J=8.0,6.9,1.1 \mathrm{~Hz}, 1 \mathrm{H}, \mathrm{Ar}), \delta 5.49(\mathrm{br} \mathrm{s}, 1 \mathrm{H}$, $\left.\mathrm{NH}_{9}\right), \delta 4.37\left(\mathrm{td}, J=4.9,1.2,1 \mathrm{H}, \mathbf{H}_{\mathrm{c}}\right), \delta 3.13(\mathrm{~d}, J=4.9 \mathrm{~Hz}, 2 \mathrm{H}$, $\mathrm{H}_{\mathrm{a}}$ and $\left.\mathrm{H}_{\mathrm{b}}\right) \cdot{ }^{13} \mathrm{C}-\mathrm{NMR}\left(101 \mathrm{MHz}, \mathrm{d}_{6}\right.$-DMSO): $\delta 175.7\left(\mathrm{C}_{2}\right), \delta$ $157.3\left(\mathrm{C}_{4}\right), \delta 135.9(\mathrm{Ar}), \delta 127.5(\mathrm{Ar}), \delta 124.1\left(\mathrm{C}_{8}\right), \delta 120.8(\mathrm{Ar})$, $\delta 118.5(\mathrm{Ar}), \delta 118.3(\mathrm{Ar}), \delta 111.2(\mathrm{Ar}), \delta 108.0\left(\mathrm{C}_{7}\right), \delta 58.3\left(\mathrm{C}_{5}\right)$, $\delta 30.6\left(\mathrm{C}_{6}\right)$. IR (neat): $\operatorname{vmax}=1704,1776 \mathrm{~cm}^{-1}(\mathrm{C}=\mathrm{O})$. 


\subsection{Biological Activity}

Antibacterial activity was studied by Mueller-Hinton agar medium for the synthesized compounds (1-3). $0.0512 \mathrm{~g}$ of each test compound was dissolved in $10 \mathrm{~mL}$ of $20 \%$ of DMSO. Two different concentrations were prepared by using half of prepared solution with $5 \mathrm{ml}$ of $20 \%$ DMSO with 256 and $512 \mu \mathrm{g} / \mathrm{mL}$ including another concentration to prepare it by $5 \mathrm{ml}$ of $20 \%$ DMSO $128 \mu \mathrm{g} / \mathrm{mL}$. Sterile cork borer (6 $\mathrm{mm}$ ) was used to prepare cups constructed in petri plates and $0.1 \mathrm{ml}$ of each tested compound was added separately into each well and then bacterial plates were incubated at $37 \mathrm{C}$ in $24 \mathrm{hrs}$. The Zone of inhibition fashioned by each compound was measured in $\mathrm{mm}$ (Table 1).

Table 1. Diameter of inhibited zones in millimeters as a measure of antibacterial activity of the synthesized compounds $(\mathbf{1}, \mathbf{2}$, and $\mathbf{3})$ and some standard drugs

\begin{tabular}{|l|c|c|c|c|c|}
\hline Compounds & \multicolumn{2}{|l|}{ Escherichia coli } & \multicolumn{2}{l|}{$\begin{array}{l}\text { Staphylococcus } \\
\text { aureus }\end{array}$} \\
\cline { 2 - 6 } & \multicolumn{2}{|l|}{$256 \mu \mathrm{g}$} & $512 \mu \mathrm{g}$ & $256 \mu \mathrm{g}$ & $512 \mu \mathrm{g}$ \\
\hline & $\mathbf{1}$ & - & - & - & 17 \\
\cline { 2 - 6 } & $\mathbf{2}$ & NA & NA & NA & NA \\
\cline { 2 - 6 } & $\mathbf{3}$ & - & - & - & 12 \\
\hline Amikacin & \multicolumn{2}{|c|}{$19-26$} & & $20-26$ & \\
\hline Cefalotin & \multicolumn{2}{|c|}{$15-21$} & & $29-37$ & \\
\hline Tetracycline & \multicolumn{2}{|c|}{$18-25$} & & $24-30$ & \\
\hline Chloramphen & $21-27$ & & $19-26$ & \\
\hline Nalidixic acid & $22-28$ & & - & \\
\hline Vancomycin & \multicolumn{2}{|c|}{-} & & $17-21$ & \\
\hline
\end{tabular}

\section{DISCUSSION}

\subsection{Chemistry}

In this study, we synthesized 5-substituted hydantoin with different substituent by reacting corresponding amino acids with urea in a free solvent. (Ware, 1950) The reaction successfully proceeded under melting condition at $170-180$ ${ }^{\circ} \mathrm{C}$ with washing by water to remove urea and amino acids. No acids and bases were used during this reaction (Scheme 2)

$$
\text { (170-180 }{ }^{\circ} \mathrm{C}
$$

Scheme 2. Synthesis of compound 1-3

Three amino acids were used as starting materials to prepare different functional groups attached to the stereogenic center. All synthesized compounds were elucidated by IR and NMR spectroscopy. Imidazolidine-2,4-dione contain two nitrogen donors and two carbonyl accepters. These functional groups have a vital role to produce hydrogen bond with the receptors. $\mathrm{N}-\mathrm{H}$ hydrogen has role to bind with solvent (Scheme 3). (Bisello et al., 2017; Etter, 1990)

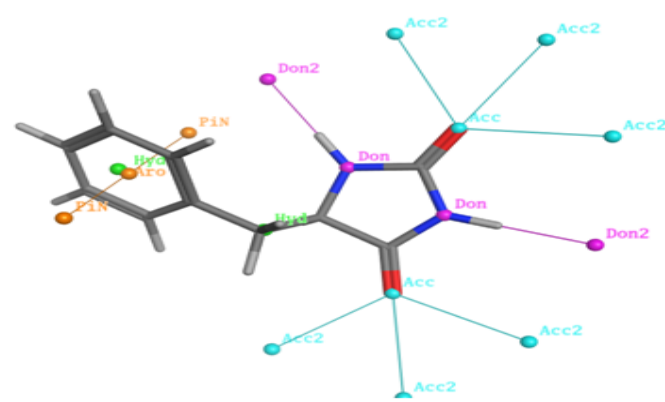

Scheme 3. 5-benzylimidazolidine-2,4-dione constraints are shown in bond acceptor, hydrogen bond donor, aromatic part of the molecule.

The hydrogen atom attached to the stereogenic center is an acidic hydrogen, Cys 76 (in thiolate form) acts as a base and retrieves a proton (vide supra), when a D-isomer of a 5-monosubstituted hydantoin is available, While, Cys 181 acts as an acid, inserting a proton in the opposite side of the substrate, thus producing Lmonosubstituted hydantoin. (Heras-Vazquez et al., 2008) Several tautomeric form could exist for 5-monosubstituted imidazolidine-2,4-dione because of presence numbers of acidic hydrogen on the structure (vide infra).

\subsection{Computational study}

The geometry of compounds were optimized using semi empirical SCF, AM1. (Dewar et al., 1985) The relative, Enthalpies and Gibbs free energies for the neutral species of compound 1, 2, and $\mathbf{3}$ have been obtained. The energy levels for all compounds were calculated by Gaussian and showed in Table 2.

Table 2. Energy profile (in $\mathrm{kcal} / \mathrm{mol}$ ) calculated at AM1

\begin{tabular}{|c|c|}
\hline Compounds & Energy $/ \mathrm{kcal} / \mathrm{mol}$ \\
\hline $\mathbf{1}$ & 133.21 \\
\hline $\mathbf{2}$ & -627.509 \\
\hline $\mathbf{3}$ & 180.0727 \\
\hline
\end{tabular}

Table 2 shows the positive values of energy for compound $\mathbf{1}$ and 3 with a dipole moments of 6.4074 , and 6.4636 debye, respectively, while a negative value for compound $\mathbf{2}$ with a dipole moment of 5.3957 debye. Substituent groups attached to position 5 predict similarity between aromatic ring substitutes such as benzene and indole rings for compound $\mathbf{1}$, and $\mathbf{3}$, respectively. There is aliphatic carbon and sulfur atom presence on the stereogenic centre for compound $\mathbf{2}$.

Based on the previous study for hydantoin derivatives, (Zaki S Safi et al., 2018; Zaki Sulieman Safi, 2012) there are several tautomeric forms could exist for imidazolidine-2,4-dione as shown in Scheme 4.<smiles>[R]c1[nH]c(=O)n(O)c1CCCC</smiles>

Scheme 4. Schematic representation of the tautomeric forms of 5-monosubstituted imidazolidine-2,4-dione.

The energy optimization geometry by AM1 were calculated when $\mathrm{R}=\mathrm{H}$ for tautomeric form from $\mathrm{A}$ to $\mathrm{E}$ (Table 3). 
Table 3. Energy profile (in $\mathrm{kcal} / \mathrm{mol}$ ) calculated at AM1

\begin{tabular}{|l|l|l|l|}
\hline $\begin{array}{l}\text { Tautomeric } \\
\text { form }\end{array}$ & $\begin{array}{l}\text { Energy/ } \\
\mathrm{kcal} / \mathrm{mol}\end{array}$ & Energy/ A.U & $\begin{array}{l}\text { Dipole moment/ } \\
\text { Debye }\end{array}$ \\
\hline A & 202.91 & 0.323364 & 6.6575 \\
\hline B & 243.69 & 0.388347 & 8.0747 \\
\hline C & 247.85 & 0.394971 & 7.1316 \\
\hline D & 206.77 & 0.32950748 & 5.9771 \\
\hline E & 137.13 & 0.218525 & 3.1113 \\
\hline
\end{tabular}

Table 3 shows the highest number of energy for tautomeric form C of $247.85 \mathrm{kcal} / \mathrm{mol}$, and the lowest energy value of $137.13 \mathrm{kcal} / \mathrm{mol}$, for compound $\mathrm{E}$. The relative stability order of the tautomeric forms of the compound (when $\mathrm{R}=\mathrm{H}$ ) under probe is as follows: $\mathrm{E}>\mathrm{D}>\mathrm{B}>\mathrm{C}$.

B3LYP with the $6-311 \mathrm{bG}(\mathrm{d}, \mathrm{p})$ has been also used to calculate energy profile for $A$ and $E$ tautomers when $R=H$ shown in supporting information.

A value of $-405805.11(\mathrm{kcal} / \mathrm{mol})$ revealed of electronic and thermal enthalpies for compound 1 (support information). The transition from keto to enol A-E is indicated in our result to show the most stable tautomor form is $\mathrm{E}$ based on the lowest energy value (Table 3). B3LYP with the 6-311pG $(d, p)$ has been also used to calculate energy profile for A and $\mathrm{E}$ tautomers when $\mathrm{R}=$ benzyl ( Compound 1 form as keto and enol form) (Table 4).

Table 4. Energy profile (in $\mathrm{kcal} / \mathrm{mol}$ ) calculated at B3LYP with the 6-311pG(d,p) (R=benzyl)

\begin{tabular}{|l|l|l|l|}
\hline $\begin{array}{l}\text { Tautomeric } \\
\text { form }\end{array}$ & $\begin{array}{l}\text { Energy/ } \\
\mathrm{kcal} / \mathrm{mol}\end{array}$ & $\begin{array}{l}\text { Energy/ } \\
\text { A.U }\end{array}$ & $\begin{array}{l}\text { Dipole } \\
\text { moment/ } \\
\text { Debye }\end{array}$ \\
\hline A & -406019.05 & -647.0324 & 6.9032 \\
\hline E & -405978.95 & -646.9685 & 7.9245 \\
\hline
\end{tabular}

Table 3 shows a low negative value for $\mathrm{E}$ (enol form) for compound 1 compare with A (keto form) showed in Scheme 4.

Finally, the IR and NMR spectra are also undertaken to study the absorption spectra of the studied compounds under probe using the time-dependent- DFT method at the B3LYP optimized structure in the gas phase.

\subsection{Docking study}

Compound 1, 2 and $\mathbf{3}$ were docked into the active site of AR (PDB ID: 2AMA) using MOE program. Glu 793 binds with compound 1 by hydrogen bond in the present of water as a solvent. In addition, Tryp 796 can also act as a base to take hydrogen attached to the streogenic centre and cause ketoenol tautomerism process (vide supra). Therefore, isomer of hydantoin as $R$ or $S$ shape will cause greater influence on the type and affinity of the binding (Scheme 5).

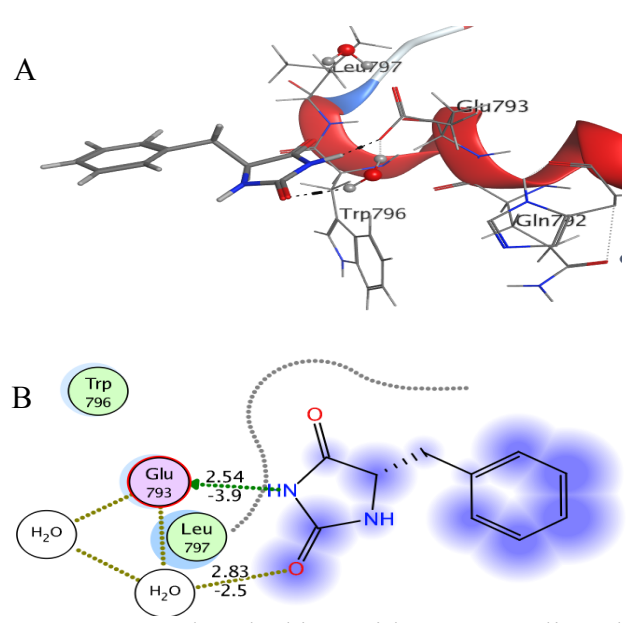

Scheme 5. Compound 1 docking with AR. Dot line show hydrogen bond between compound and amino acids or water. B) Cycled line shows a Latch interaction between Leu 797 and compound 1. Values over the dot lines show distance of the bond, while negative values under dot lines indicate energy of the bond.
Compound 2 has been also docked with AR and shows complex with Glu 793 by hydrogen bond in the presence of water as a solvent in the position of N-3. Sulfur atom attached to the ethyl group on the position 5 can also bind with ARG 786 by a weak bond (H-Accepter) and a distance of the bond 5.30, and -0.7 $\mathrm{Kcal} / \mathrm{mol}$ ). Trp 796 binds with molecule by H-pi bond with the distance of 4.33 and energy of $-0.9 \mathrm{Kcal} / \mathrm{mol}$ ) (Schem 6).
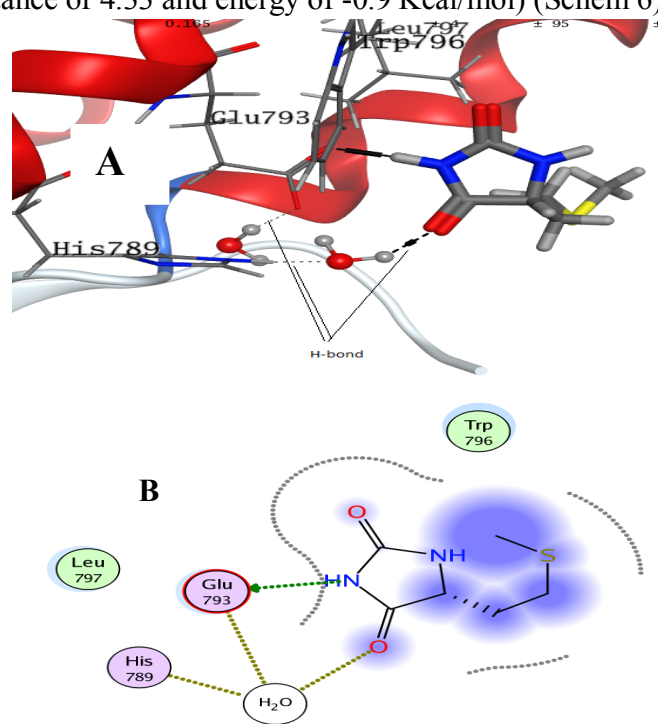

Scheme 6. A) Compound 2 docking with AR. Dot line show hydrogen bond between compound and amino acids or water. B) Cycled line shows a Latch interaction between Leu 797 and compound 2.

Compound 3 has similar docking at $\mathrm{N}-3$ position by $\mathrm{H}$-bond with Glu 793 with the distance of 2.46 and energy of $0.6 \mathrm{Kcal} / \mathrm{mol}$. Two carbonyl groups at the positions of 2, and 4 act as electron accepters and accept hydrogens from water in addition of the connection with Glu 793 by hydrogen bonds. Trp 796 binds with aromatic ring by H-pi bond at the distance of 3.61 and energy of $-0.7 \mathrm{Kcal} / \mathrm{mol}$ (Scheme 7).

A

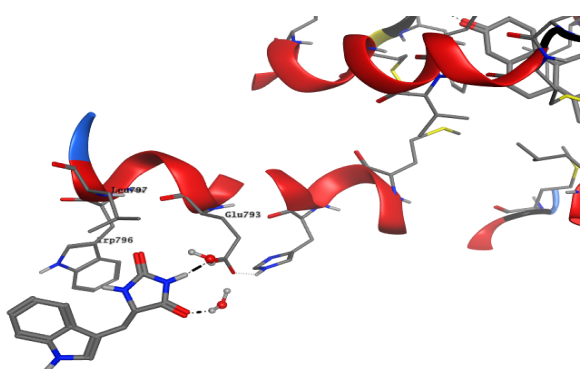

B

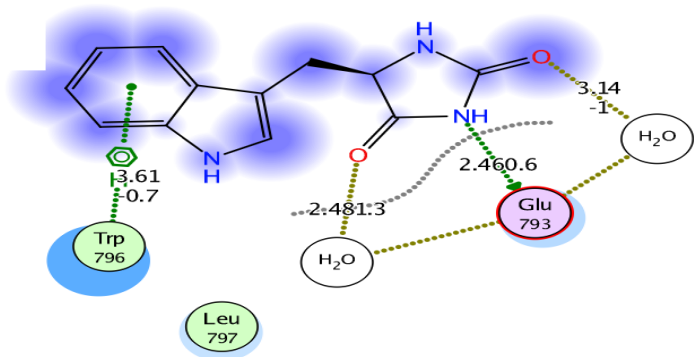

Scheme 7. A) Compound 3 docking with AR. Dot line show hydrogen bond between compound and amino acids or water. B Cycled line shows a Latch interaction between Glu793 and compound 3. Values over the dot lines show distance of the bond, while negative values under dot lines indicate energy of the bond.

\subsection{Biological activity}

Biological activity of the present compounds in terms of antibacterial property was analyzed against two well-known 
pathogenic gram-negative and gram-positive organisms such as Escherichia coli, and Staphylococcus aureus, respectively.

The activity was tested after dissolution of all the compounds $\mathbf{1}$ and $\mathbf{3}$ in DMSO, which was used as a negative control in the experiment. The results of the bacterial growth inhibition are shown in Table 1 (vide supra) along with the corresponding positive and negative controls. Compounds $\mathbf{1}$, and $\mathbf{3}$ showed significant growth inhibition of 17 and $12 \mathrm{~mm}$, respectively against Staphylococcus aureus, indicating that the experimental set and procedures are appropriate for the test (Table 1)

\section{CONCLUSIONS}

In this study, three 5-substituted imidazolidine-2,4-diones have been synthesized under free solvent condition. We have performed a theoretical study on the stability order and the prototrophic isomerization processes of using Gaussian program with B3LYP with the $6-311 \mathrm{pG}(\mathrm{d}, \mathrm{p})$ and AM1. The cyclic imidazolidine-2,4-dione derivatives have been investigated. Molecular docking was performed to simulate the modes of interactions between the drugs and Androgen receptor. Two carbonyl groups at the positions of 2 , and 4 act as electron accepters and accept hydrogens from water in addition of the connection with Glu 793 by hydrogen bonds from N-3 position. The best output poses of the ligands generated were analyzed on the basis of Molecular operating environment (MOE), feasibility of hydride transfer process, and H-bonding to the enzyme. Compounds $\mathbf{1}$, and $\mathbf{3}$ showed significant growth inhibition of 17 and $12 \mathrm{~mm}$, respectively against gram positive bacteria, Staphylococcus aureus, and resistance to the gram-negative bacteria.

\section{ACKNOWLEDGEMENTS}

The co-author will always thank Dr Niklaas Buurma at Cardiff University for help during his phD as a supervisor for giving a wide information.

\section{REFERENCES}

Baeyer, Adolph. (1861). Vorläufige Notiz über das Hydantoïn. Justus Liebigs Annalen der Chemie, 117(2), 178-180.

Becke, Axel D. (1993). Density-functional thermochemistry. III. The role of exact exchange. The Journal of chemical physics, 98(7), 5648-5652.

Bisello, Annalisa, Cardena, Roberta, Rossi, Serena, Crisma, Marco, Formaggio, Fernando, \& Santi, Saverio. (2017). Hydrogen-Bond-Assisted, Concentration-Dependent Molecular Dimerization of Ferrocenyl Hydantoins. Organometallics, 36(11), 2190-2197.

Cheng, Cheng-Kuo, Wu, Jender, Liu, Yuan, Lee, Tong-Sheng, Kang, Shuo-Jhen, Sheu, Ming-Thau, \& Lee, Wen-Sen. (2008). Structure and anti-proliferation function of 5, 5-diphenyl2-thiohydantoin (DPTH) derivatives in vascular endothelial cells. Vascular pharmacology, 48(2-3), 138142.

Colacino, Evelina, Lamaty, Frédéric, Martinez, Jean, \& Parrot, Isabelle. (2007). Microwave-assisted solid-phase synthesis of hydantoin derivatives. Tetrahedron letters, 48(30), 5317-5320.

Dewar, Michael JS, Zoebisch, Eve G, Healy, Eamonn F, \& Stewart, James JP. (1985). Development and use of quantum mechanical molecular models. 76. AM1: a new general purpose quantum mechanical molecular model. Journal of the American Chemical Society, 107(13), 3902-3909.

Etter, Margaret C. (1990). Encoding and decoding hydrogen-bond patterns of organic compounds. Accounts of Chemical Research, 23(4), 120-126.

Frisch, M. J., Trucks, G. W., Schlegel, H. B., Scuseria, G. E., Robb, M. A., Cheeseman, J. R., . . . Fox, D. J. (2016). Gaussian 16 Rev. B.01. Wallingford, CT.
Gao, Wenqing, Bohl, Casey E, \& Dalton, James T. (2005). Chemistry and structural biology of androgen receptor. Chemical reviews, 105(9), 3352-3370.

Ghanbari, Mohammad M, Roohi, Zahra, \& Safari, Javad. (2014). Onepot synthesis of imidazolidine-2-thiones, hydantoins and thiohydantoins under solvent-free and grinding conditions. Open Access Library Journal, 1(07), 1.

Heras-Vazquez, Francisco JL, Clemente-Jimenez, Josefa M, MartinezRodriguez, Sergio, \& Rodriguez-Vico, Felipe. (2008). Optically pure $\alpha$-amino acids production by the "Hydantoinase Process". Recent patents on biotechnology, 2(1), 35-46

Katritzky, Alan R, Strah, Sonja, \& Belyakov, Sergei A. (1998). The preparation of functionalized amines and amides using benzotriazole derivatives and organozinc reagents. Tetrahedron, 54(25), 7167-7178.

Law, Vivian, Knox, Craig, Djoumbou, Yannick, Jewison, Tim, Guo, An Chi, Liu, Yifeng, . . . Neveu, Vanessa. (2013). DrugBank 4.0: shedding new light on drug metabolism. Nucleic acids research, 42(D1), D1091-D1097.

Li, Jie Jack. (2010). Name reactions: a collection of detailed mechanisms and synthetic applications: Springer Science \& Business Media.

Nefzi, Adel, Giulianotti, Marc A, \& Houghten, Richard A. (2000). Solidphase synthesis of branched thiohydantoin benzimidazolinethiones and branched thiohydantoin tetrahydroquinoxalinediones. Tetrahedron Letters, 41(14), 2283-2287.

Nique, François, Hebbe, Séverine, Peixoto, Christophe, Annoot, Denis, Lefrançois, Jean-Michel, Duval, Eric, . . . Mollat, Patrick. (2012). Discovery of diarylhydantoins as new selective androgen receptor modulators. Journal of medicinal chemistry, 55(19), 8225-8235.

Pereira de Jesus-Tran, K., Cote, P. L., Cantin, L., Blanchet, J., Labrie, F., \& Breton, R. (2006). Comparison of crystal structures of human androgen receptor ligand-binding domain complexed with various agonists reveals molecular determinants responsible for binding affinity. Protein Sci, 15(5), 987-999. doi: $10.1110 /$ ps.051905906

Safari, J, Naeimi, H, Ghanbari, MM, \& Fini, O Sabzi. (2009). Preparation of phenytoin derivatives under solvent-free conditions using microwave irradiation. Russian journal of organic chemistry, 45(3), 477-479.

Safari, Javad, Moshtael Arani, Naimeh, \& Ramezan Isfahani, Anousheh. (2010). Ultrasound-enhanced Green Synthesis of 5, 5Diphenylhydantoin Derivatives Using Symmetrical or Unsymmetrical Benzils. Chinese Journal of Chemistry, 28(2), 255-258.

Safi, Zaki S, Al Hasanat, Subhia J, \& Wazzan, Nuha A. (2018). DFT investigation of the amino/imino proton transfer process of 2 amino-2-oxazolin-4-one in gas phase and solution. Journal of Theoretical and Computational Chemistry, 17(01), 1850004.

Safi, Zaki Sulieman. (2012). Theoretical density functional study of gasphase tautomerization and acidity of 5-methylhydantoin and its thio derivatives. European Journal of Chemistry, 3(3), 348-355.

Tikhonov, Denis B, \& Zhorov, Boris S. (2017). Mechanism of sodium channel block by local anesthetics, antiarrhythmics, and anticonvulsants. The Journal of general physiology, 149(4), 465-481

Ware, Elinor. (1950). The chemistry of the hydantoins. Chemical Reviews, 46(3), 403-470.

Zhang, Mao, Liang, Yu-Ru, Li, Huan, Liu, Ming-Ming, \& Wang, Yang. (2017). Design, synthesis, and biological evaluation of hydantoin bridged analogues of combretastatin A-4 as potential anticancer agents. Bioorganic \& medicinal chemistry, 25(24), 6623-6634

Zhang, Xuqing, Allan, George F, Sbriscia, Tifanie, Linton, Olivia, Lundeen, Scott G, \& Sui, Zhihua. (2006). Synthesis and SAR of novel hydantoin derivatives as selective androgen receptor modulators. Bioorganic \& medicinal chemistry letters, 16(22), 5763-5766.

Zuo, Minzan, Xu, Xi, Xie, Zhouling, Ge, Raoling, Zhang, Ziyu, Li, Zhiyu, \& Bian, Jinlei. (2017). Design and synthesis of indoline thiohydantoin derivatives based on enzalutamide as antiproliferative agents against prostate cancer. European journal of medicinal chemistry, 125, 1002-1022. 